\title{
Osviještenost studentica Zdravstvenog veleučilišta o samopregledu dojke
}

1 Antonija Šajnović

1 Ema Šerkić

1 Matea Dumančić

1 Ana Brčina

2 Snježana Čukljek

1 Zdravstveno veleučilište Zagreb, studentice studija sestrinstva

2 Zdravstveno veleučilište Zagreb

\section{Sažetak}

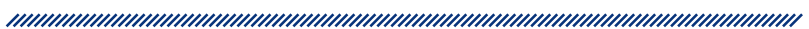

Rak dojke glavno je sijelo raka ženske populacije u Republici Hrvatskoj, a incidencija i mortalitet znatno su viši od europskog standarda. Prakticiranjem provođenja samopregleda svakog mjeseca rak dojke može se otkriti u ranijoj fazi nego kod žena koje ga ne obavljaju. Pokazalo se da je rano otkrivanje povezano sa smanjenjem morbiditeta i mortaliteta od raka dojke. lako je samopregled dojke jednostavan za obavljanje, kratko traje i nema troškova, većina ga žena obavlja pogrešno ili ga uopće ne obavlja.

Svrha ovog istraživanja bila je procijeniti znanje, stav i učestalost obavljanja samopregleda dojke među studenticama Zdravstvenog veleučilišta u Zagrebu. Podaci su prikupljeni s pomoću upitnika koji je sadržavao sociodemografske podatke i 13 pitanja. $U$ istraživanje je uključeno 528 studentica prve, druge i treće godine studija svih redovnih smjerova (medicinsko-laboratorijska dijagnostika, fizioterapija, sestrinstvo, radiološka tehnologija, sanitarno inženjerstvo i radna terapija).
Rezultati ukazuju da većina studentica ne obavlja samopregled. Mjesečno ga obavlja samo 32,89 \% studentica. Kao najčešći razlog za neobavljanje navode da misle da su premlade, a $24,43 \%$ studentica tvrdi da ne zna obaviti samopregled.

Potrebno je u nastavne sadržaje uključiti više predavanja o preventivnim postupcima, pravilnom izvođenju samopregleda te važnosti ranog otkrivanja raka dojke, kako bi znanje mogli primijeniti na sebi, a i kao budući zdravstveni djelatnici na pacijente. Također je potrebno organizirati što više preventivnih akcija i uključivati studente zdravstvenih struka u njih kako bi se veći broj mladih žena osvijestio o važnosti ranog otkrivanja raka dojke.

Ključne riječi: samopregled dojke, preventivne mjere, karcinom dojke

Datum primitka: 04.08.2018.

Datum prihvaćanja: 15.10.2018.

DOI: $10.24141 / 1 / 4 / 2 / 10$

Adresa za dopisivanje:

Antonija Šajnović

tel.: +385996389652

e-pošta: antonija.sajnovic1@gmail.com 


\section{Uvod}

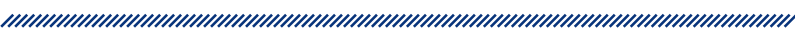

Novotvorina, neoplazma, tumor ili rak sinonimi su za patološku tvorbu koja je nastala kao posljedica prekomjerne diobe abnormalnih stanica; stanica čiji rast nadmašuje rast normalnih tkiva te je biološki nesvrhovit, nepravilan i neorganiziran. Broj oboljelih i umrlih od malignih bolesti u stalnom je porastu, pojedine statistike navode da svaka treća osoba obolijeva od maligne bolesti, a svaka četvrta umire. ${ }^{1}$

Rak dojke najčešće je sijelo raka u žena i čini $26 \%$ novih slučajeva raka. Incidencija je 119,2, što je znatno više od europskog standarda, koji je 89,4. Isto tako, mortalitet u Republici Hrvatskoj iznosi 48,3, a europska je standardna stopa $28,7 .^{2}$

Karcinom in situ dojke kategorizira se na lobularni i duktalni karcinom dojke. Učestalost je lobularnog raka in situ od $1 \%$ do 3,8 \% svih karcinoma dojke. Lezija je pronađena u 0,5 do $4 \%$ svih benignih biopsija dojke. Najčešće se javlja u dobi od 15 do 90 godina, ali većina se dijagnosticira u premenopauzi. ${ }^{3}$ Upečatljiv rast u otkrivanju duktalnog raka in situ proizašao je iz svima dostupne mamografije i povećavanja svijesti o raku dojke u općoj populaciji. Podaci iz Nacionalnog epidemiološkog instituta za nadzor raka iz SAD-a, govore da se udio karcinoma dojke dijagnosticiranih kao DCIS povećao s 2,8 \% (1973. godina) na $14,4 \%$ (1995. godina). ${ }^{3}$ Pod pojmom dobroćudni tumori dojke smatra se heterogena skupina lezija koja se prezentira različitom kliničkom slikom, a također se pronađu slučajno tijekom pregleda. Pred kraj dvadesetog stoljeća incidencija tumora dojke počinje rasti, većinom pogađa žene u dobi od 40 do 50 godina. Najčešća je neoplazma iz te skupine fibrocistična bolest dojke. Zahvaća žene u razdoblju premenopauze u dobi od 20 do 50 godina. Još je jedna u nizu čestih neoplazmi iz iste skupine fibroadenom dojke. Javlja se u $25 \%$ žena koje su asimptomatske i često je to tumor rane reproduktivne dobi s vrhom incidencije između 15 i 35 godina. Ostali su tumori iz te skupine koji se javljaju vrlo rijetko tumor granularnih stanica i hamartom. ${ }^{4}$ U razvijenim zemljama rak dojke odgovoran je za oko četvrtinu novih slučajeva raka u žena. ${ }^{5}$ Rak dojke u Hrvatskoj je najčešći uzrok smrti od raka u žena te najčešći pojedinačni uzrok smrti općenito u žena u dobi od 35 do 64 godina. $^{5}$

Mjesec borbe protiv raka dojke održava se u listopadu, a 7. listopada proglašen je i Danom borbe protiv raka doj- ke. Rak dojke nije samo fizička bolest. Žene često teško prihvaćaju dijagnozu, ponekad nemaju potporu najbližih ili radne okoline. Stoga se razgovorom i pisanjem o toj bolesti nastoji osvijestiti sve pripadnike društva. Svaka žena ima rizik za pojavu raka dojke, no postoje čimbenici rizika na koje žene mogu djelovati. Zdrav stil života ima važnu ulogu u prevenciji raka dojke. Pravilna prehrana i tjelesna aktivnost najvažnije su mjere primarne prevencije.

Samopregled dojke jednostavna je, besplatna, kratka i učinkovita metoda prevencije ili pak ranog otkrivanja mastopatija ili drugih mogućih neoplazmi tkiva dojke. Provodi se jednom mjesečno u određenoj fazi menstrualnog ciklusa jer dojke moraju biti opuštene, a i same su kvržice najizraženije uoči menstruacije, budući da su ovisne o menstrualnom ciklusu. Zato je važno da se samopregled uvijek provodi u istoj fazi ciklusa, pred kraj ili neposredno poslije menstruacije, kada se dojke opuste. Kod nekih je žena to već treći dan ciklusa, kod drugih sedmi ili osmi. ${ }^{6}$ Cilj je pregleda upoznati strukturu dojke i uočiti eventualne zabrinjavajuće promjene. Samopregled se sastoji od nekoliko faza. Prva je faza inspekcija. Dojke prvenstveno treba dobro promotriti u zrcalu. Promatrati izgled kože i bradavica, pomičnost dojki pri podizanju obiju ruku, posebno pomičnost i izgled kože kada pojedinu dojku pomičemo u raznim smjerovima. Drugi je dio samopregleda pipanje dojki. Najbolje ga je provoditi i u sjedećem i ležećem položaju, budući da se neke promjene mogu bolje napipati u određenom položaju. Osnovno je pravilo da desna ruka uvijek pipa lijevu dojku, a lijeva desnu. Pritom je vrlo važno spojiti jagodice dva ili tri prsta kako bi se povećala površina pipanja i izbjegla mogućnost da male kvržice ostanu neotkrivene. Iznimno je važno maksimalno poboljšati kontakt između prstiju i kože na dojci. Osim pregleda dojki, samopregled uključuje i palpaciju limfnih čvorova te kontrolu eventualnog iscjetka iz dojki. ${ }^{6}$ Raznim preventivnim akcijama promovira se samopregled te se nastoji probuditi svijest o važnosti ranog otkrivanja raka dojke. Studentice Zdravstvenog veleučilišta, kao buduće zdravstvene djelatnice, moraju propagirati mjere primarne i sekundarne prevencije. Cilj je ovog istraživanja procijeniti znanje, stav i učestalost obavljanja samopregleda dojke među studenticama Zdravstvenog veleučilišta u Zagrebu. 


\section{Metode}

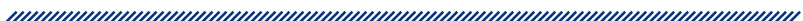

U 2017. godini provedeno je presječno istraživanje o osviještenosti o samopregledu dojke na 528 studentica Zdravstvenog veleučilišta u Zagrebu. Primijenjene su metode deskriptivne statistike, frekvencija i relativna frekvencija. Dobivena je suglasnost Etičkog povjerenstva Zdravstvenog veleučilišta. $U$ istraživanju su najveći udio zauzele studentice druge godine i studentice studija sestrinstva.

\begin{tabular}{|c|c|c|}
\hline \multicolumn{3}{|c|}{$\begin{array}{c}\text { Tablica 1. Struktura ispitanica s obzirom na } \\
\text { godinu studija }\end{array}$} \\
\hline GODINA STUDIJA & $\mathrm{N}$ & $\%$ \\
\hline 1. godina & 183 & $34,66 \%$ \\
\hline 2. godina & 217 & $41,10 \%$ \\
\hline 3. godina & 128 & $24,24 \%$ \\
\hline UKUPNO & 528 & $100,00 \%$ \\
\hline
\end{tabular}

\begin{tabular}{|c|c|c|}
\hline SMJER STUDIJA & $\mathrm{N}$ & $\%$ \\
\hline Studij sestrinstva & 184 & $34,85 \%$ \\
\hline Studij fizioterapije & 74 & $14,02 \%$ \\
\hline $\begin{array}{l}\text { Studij medicinsko-laboratorijske } \\
\text { dijagnostike }\end{array}$ & 72 & $13,64 \%$ \\
\hline Studij sanitarnog inženjerstva & 117 & $22,16 \%$ \\
\hline Studij radne terapije & 17 & $3,22 \%$ \\
\hline Studij radiološke tehnologije & 64 & $12,12 \%$ \\
\hline UKUPNO & 528 & $100,00 \%$ \\
\hline
\end{tabular}

Upitnik koji je primijenjen obuhvaća sociodemografske podatke i 13 pitanja zatvorenog tipa, a izrađen je za potrebe ovog istraživanja. $U$ anketi su ispitanicama bila postavljena pitanja o tome je li netko u njihovoj obitelji bolovao od raka dojke, jesu li upoznate s postupkom samopregleda dojke, gdje su dobile informacije, znaju li obaviti samopregled dojke te obavljaju li ga, koji je razlog za neobavljanje, u kojoj se fazi menstrualnog ciklusa obavlja samopregled, koliko ga često obavljaju te smatraju li da je važno obavljati samopregled dojke u ranoj životnoj dobi. Također su postavljena pitanja o odazivanju na preventivne akcije, postoji li dovoljno edukativnih materijala i preventivnih akcija, je li ih ovaj upitnik naveo na razmišljanje te bi li voljele da se na njihovu fakultetu održi predavanje o samopregledu i incidenciji raka dojke. Anketni podaci prikupljeni su na Zdravstvenom veleučilištu u pisanoj formi. Svim je sudionicima napomenuta anonimnost upitnika. $U$ istraživanje su uključene studentice $u$ dobi od 18 do 31 godine, najviše ih je bilo u dobi od 20 i 21 godine. Dobna struktura bila sljedeća:

\begin{tabular}{|c|c|c|}
\hline \multicolumn{3}{|c|}{ Tablica 3. Struktura ispitanica s obzirom na } \\
dob
\end{tabular}

\begin{tabular}{|c|c|c|}
\hline $\begin{array}{l}\text { PRETHODNO ZAVRŠENO } \\
\text { OBRAZOVANJE }\end{array}$ & $\mathrm{N}$ & $\%$ \\
\hline Medicinska škola & 129 & $24,43 \%$ \\
\hline Gimnazija & 347 & $65,72 \%$ \\
\hline Ostalo & 52 & $9,85 \%$ \\
\hline UKUPNO & 528 & $100,00 \%$ \\
\hline
\end{tabular}

\section{Rezultati}

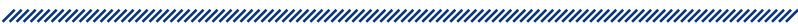

Kod $19,13 \%(\mathrm{n}=101)$ studentica postoji pozitivna obiteljska anamneza o karcinomu dojke.

\begin{tabular}{|c|c|c|}
\hline \multicolumn{3}{|c|}{$\begin{array}{c}\text { Tablica 5. Je li netko u vašoj obitelji bolovao } \\
\text { od raka dojke (majka, baka, sestra...)? }\end{array}$} \\
\hline & DA & NE \\
\hline Sestrinstvo & $34(18,48 \%)$ & $150(81,52 \%)$ \\
\hline Fizioterapija & $23(31,08 \%)$ & $51(68,92 \%)$ \\
\hline Radiološka tehnologija & $10(15,63 \%)$ & $54(84,38 \%)$ \\
\hline Sanitarno inženjerstvo & $16(13,91 \%)$ & $99(86,09 \%)$ \\
\hline $\begin{array}{c}\text { Medicinsko-laboratorijska } \\
\text { dijagnostika }\end{array}$ & $12(16,67 \%)$ & $60(83,33 \%)$ \\
\hline Radna terapija & $6(35,29 \%)$ & $11(64,71 \%)$ \\
\hline Ukupno & $101(19,13 \%)$ & $425(80,49 \%)$ \\
\hline Neodgovoreno & $2(0,38 \%)$ & \\
\hline
\end{tabular}


Nadalje, u tablici 6 možemo vidjeti da je sa samopregledom dojke upoznato $87,50 \%(n=462)$ studentica, najveći broj studentica sa studija sestrinstva i fizioterapije, njih više od $90 \%$, dok je sa studija radne terapije i medicinsko-laboratorijske dijagnostike upoznat najmanji broj studentica.

\begin{tabular}{|c|c|c|}
\hline \multicolumn{3}{|c|}{$\begin{array}{c}\text { Tablica } 6 . \text { Jeste li upoznati s postupkom } \\
\text { samopregleda dojke? }\end{array}$} \\
\hline & DA & NE \\
\hline Sestrinstvo & $169(91,85 \%)$ & $15(8,15 \%)$ \\
\hline Fizioterapija & $68(91,89 \%)$ & $6(8,11 \%)$ \\
\hline Radiološka tehnologija & $52(83,87 \%)$ & $10(16,13 \%)$ \\
\hline Sanitarno inženjerstvo & $106(89,83 \%)$ & $12(10,17 \%)$ \\
\hline Medicinsko-laboratorijska & $56(78,87 \%)$ & $15(21,13 \%)$ \\
\hline dijagnostika & $11(64,71 \%)$ & $6(32,29 \%)$ \\
\hline Radna terapija & $462(87,5 \%)$ & $64(12,12 \%)$ \\
\hline Ukupno & $2(0,38 \%)$ \\
\hline Neodgovoreno &
\end{tabular}

Informacije su dobile uglavnom s predavanja (45,68 \%, $\mathrm{n}=259)$ i interneta $(30,34 \%, \mathrm{n}=172)$. Samo $15,17 \%$ ( $\mathrm{n}=86$ ) studentica informaciju o važnosti samopregleda dojke dobilo je od liječnika ili medicinske sestre (grafikon 1).

Kako se obavlja samopregled zna 73,48 \% ( $n=388)$ studentica, a postotak studentica koje znaju obavljati samopregled ne raste $s$ godinama studija (tablica 7 ). Najveći dio studentica sestrinstva $(81,61 \%, n=142)$ i sanitarnog inženjerstva $(80,34 \%, n=94)$ zna kako obaviti samopregled, studentice fizioterapije 68,92\% $(n=51)$, radiološke tehnologije $73,44 \%(n=47)$, dok najmanji dio čine studentice medicinsko-laboratorijske dijagnostike $(61,97 \%, n=44)$ i radne terapije $(58,82 \%, n=10)$.

\begin{tabular}{|c|c|c|}
\hline \multicolumn{3}{|c|}{ Tablica 7. Znate li obaviti samopregled } \\
dojke?
\end{tabular}

Samopregled obavlja samo $47,35 \%$ studentica, najmanje ih obavlja na prvoj godini studija $(40,44 \%, n=74)$, a najviše na drugoj godini $(55,76 \%, n=121)$. Iz grafikona 2 možemo vidjeti da je najveći postotak studentica koje obavljaju samopregled sa studija sestrinstva, njih 52,17\% ( $n=96)$, a najmanje sa studija fizioterapije, njih 39,19\% $(n=29)$. Kao najčešći razlog za neobavljanje navode da misle da su premlade i manjak edukacije (grafikon 3).

Većina ispitanica navodi da ne zna u kojoj se fazi obavlja samopregled dojke, ukupno po studijima od $39,08 \%$ do $76,47 \%(n=288)$, a samo $19,22 \%(n=103)$ navodi da se obavlja u prvoj fazi menstrualnog ciklusa.

Iz tablice 9 možemo vidjeti da jednom mjesečno samopregled obavlja samo $32,89 \%$ ispitanica $(n=173)$, jednom godišnje $19,96 \%(n=105)$, a čak $41,44 \%(n=218)$ studentica nikad ne obavlja samopregled.

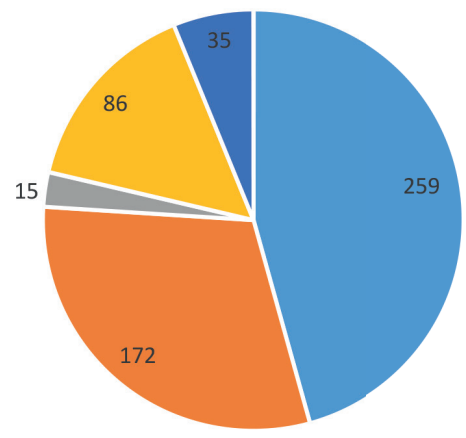

- Predavanja $\quad$ Internet $\quad$ Od prijatelja = Od liječnika / medicinske sestre $\quad$ Ostalo 


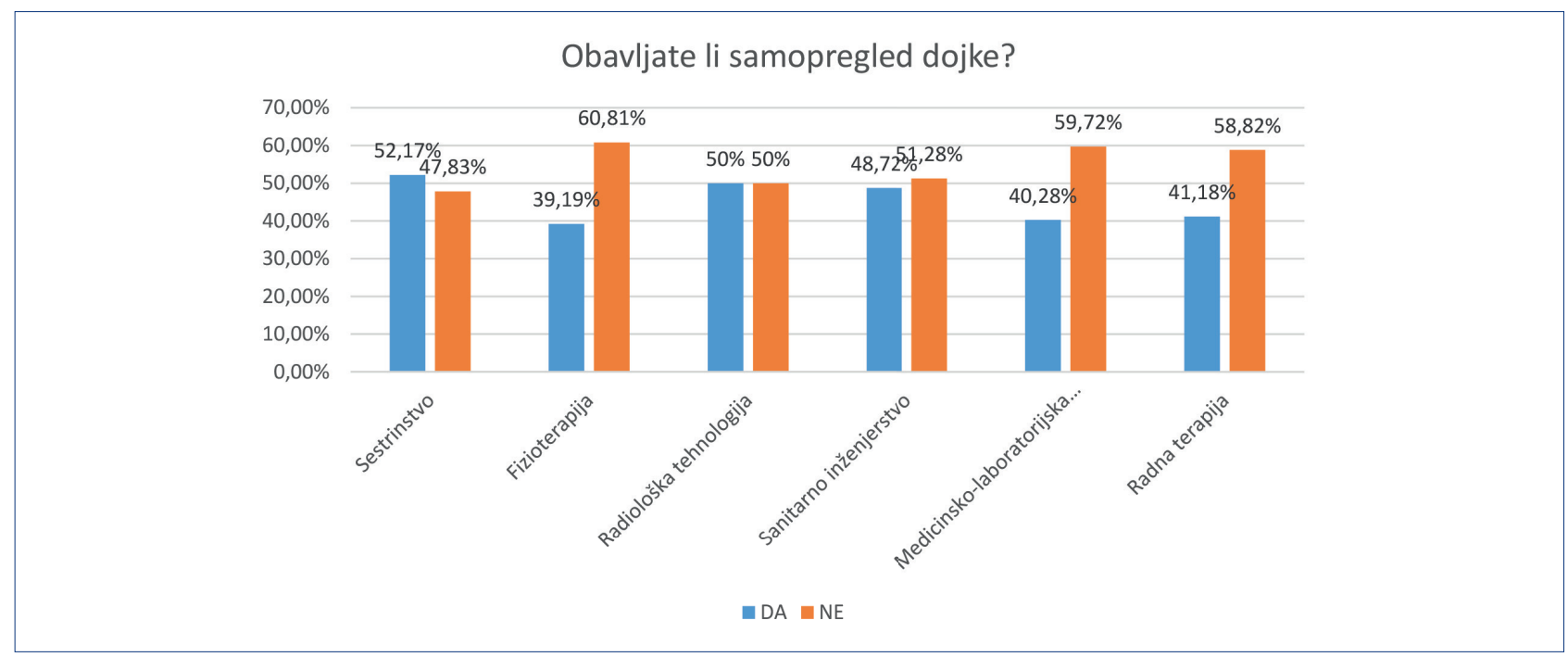

Grafikon 2. Obavljate li samopregled dojke?

Ako ne obavljate samopregled dojke, koji je razlog?

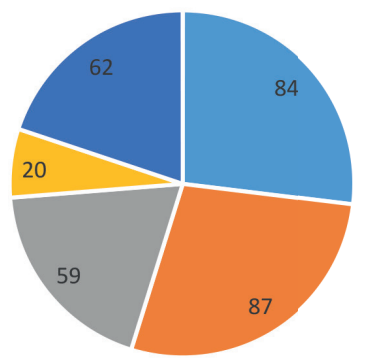

- Manjak edukacije
- Nisam zainteresirana
- Ostalo

- Smatram da sam premlada

- Mislim da se meni to ne može dogoditi

Grafikon 3. Ako ne obavljate samopregled dojke, koji je razlog?

Da je pregled važno obavljati u ranoj životnoj dobi smatra $91,12 \%(n=482)$ ispitanica, od 18 do 25 godina. Stav da ne postoji dovoljno edukacijskih materijala i preventivnih akcija o samopregledu i važnosti zdravlja dojke zauzelo je 51,14\% ( $=270)$ studentica. Njih 85,82 \% ( $n=357)$ se ne odaziva na postojeće preventivne akcije. Upitnik primijenjen u istraživanju naveo je $80,31 \%$ ( $n=359)$ studentica na razmišljanje o samopregledu dojki. Da se na njihovom fakultetu održi predavanje o samopregledu i incidenciji raka dojke željelo bi $84,88 \%$ $(n=376)$ ispitanih studentica.

\section{Rasprava}

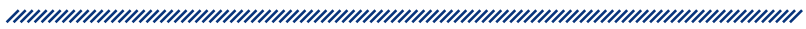

Sa samopregledom dojke upoznato je $87,50 \%$ studentica. Informacije su dobile uglavnom s predavanja $(45,68 \%)$ i interneta (30,34 \%), a samo $15,17 \%$ studentica informaciju o važnosti samopregleda dojke dobilo je od liječnika ili medicinske sestre. Samopregled nikad ne obavlja čak 41,44\% studentica, taj postotak pada s godinama studija, gdje na prvoj godini iznosi $50,00 \%$, na drugoj $33,03 \%$, a na trećoj $43,75 \%$. 


\begin{tabular}{|c|c|c|c|c|}
\hline \multicolumn{5}{|c|}{ Tablica 8 . U kojoj se fazi menstrualnog ciklusa obavlja samopregled dojke? } \\
\hline & U prvoj & U drugoj & U trećoj & Ne znam \\
\hline 1. godina & $37(20,67 \%)$ & $26(14,53 \%)$ & $18(10,06 \%)$ & $98(54,75 \%)$ \\
\hline 2. godina & $38(16,59 \%)$ & $51(22,27 \%)$ & $28(12,23 \%)$ & $112(48,91 \%)$ \\
\hline 3. godina & $28(21,86 \%)$ & $10(7,81 \%)$ & $12(9,36 \%)$ & $78(60,94 \%)$ \\
\hline Sestrinstvo & $48(27,59 \%)$ & $40(22,99 \%)$ & $18(10,34 \%)$ & $68(39,08 \%)$ \\
\hline Fizioterapija & $5(5,81 \%)$ & $16(18,60 \%)$ & $17(19,77 \%)$ & $48(55,81 \%)$ \\
\hline Radiološka tehnologija & $21(30,00 \%)$ & $10(14,29 \%)$ & $3(4,29 \%)$ & $36(51,43 \%)$ \\
\hline Sanitarno inženjerstvo & $15(13,00 \%)$ & $13(11,11 \%)$ & $13(11,11 \%)$ & $76(64,96 \%)$ \\
\hline $\begin{array}{c}\text { Medicinsko- } \\
\text { laboratorijska }\end{array}$ & $11(15,28 \%)$ & $7(9,72 \%)$ & $7(9,72 \%)$ & $47(65,28 \%)$ \\
\hline dijagnostika & $3(17,65 \%)$ & $1(5,88 \%)$ & $0(0,00 \%)$ & $13(76,47 \%)$ \\
\hline Radna terapija & $103(19,22 \%)$ & $87(16,23 \%)$ & $58(10,82 \%)$ & $288(53,73 \%)$ \\
\hline Ukupno & & & & \\
\hline
\end{tabular}

\begin{tabular}{|c|c|c|c|c|}
\hline \multicolumn{5}{|c|}{ Tablica 9. Koliko čsto obavljate samopregled dojke? } \\
\hline & Jednom tjedno & Jednom mjesečno & Jednom godišnje & Nikad \\
\hline 1. godina & $6(3,33 \%)$ & $52(28,89 \%)$ & $32(17,78 \%)$ & $90(50,00 \%)$ \\
\hline 2. godina & $17(7,80 \%)$ & $80(36,70 \%)$ & $49(22,48 \%)$ & $72(33,03 \%)$ \\
\hline 3. godina & $7(5,47 \%)$ & $41(32,03 \%)$ & $24(18,75 \%)$ & $56(43,75 \%)$ \\
\hline Sestrinstvo & $17(9,39 \%)$ & $63(34,81 \%)$ & $33(18,23 \%)$ & $68(37,57 \%)$ \\
\hline Fizioterapija & $1(1,35 \%)$ & $21(28,38 \%)$ & $15(20,27 \%)$ & $37(50,00 \%)$ \\
\hline Radiološka tehnologija & $1(1,56 \%)$ & $17(26,56 \%)$ & $19(29,69 \%)$ & $27(42,19 \%)$ \\
\hline Sanitarno inženjerstvo & $5(4,27 \%)$ & $50(42,74 \%)$ & $16(13,68 \%)$ & $46(39,32 \%)$ \\
\hline Medicinsko- & & & & $20(27,40 \%)$ \\
\hline laboratorijska & $6(8,22 \%)$ & $17(23,29 \%)$ & $2(11,76 \%)$ & $30(41,10 \%)$ \\
\hline dijagnostika & $0(0,00 \%)$ & $5(29,41 \%)$ & $105(19,96 \%)$ & $10(58,82 \%)$ \\
\hline Radna terapija & $30(5,70 \%)$ & $173(32,89 \%)$ & $218(41,44 \%)$ \\
\hline Ukupno & & & & \\
\hline
\end{tabular}

Na svim studijima kroz razne kolegije naglašava se važnost preventivnih mjera. Studenti sestrinstva kroz kolegije Javno zdravstvo, Zdravstvena njega majke i novorođenčeta na drugoj godini studija i Zdravstvena njega onkoloških bolesnika na trećoj godini studija, obrađuju gradivo o samopregledu dojke, ali ne prolaze taj dio na predavanjima, već se spominje u obveznoj literaturi. Veliki broj studentica sestrinstva upoznat je s postupkom obavljanja samopregleda dojke (91,85\%), dok ga obavlja samo $52,17 \%$ studentica.

Slično istraživanje provedeno je među studenticama sveučilišta Ahmadu Bello Zaria u Nigeriji. Rak dojke također je veliki javnozdravstveni problem u ovoj državi te su istraživači odlučili procijeniti znanje i praksu izvođenja samopregleda dojki. Vjeruje se da žene tamne puti imaju veći rizik za nastanak ovog karcinoma za razliku od onih bijele rase, također se prije razvija lezija s većom masom otpornijom na liječenje. ${ }^{7} \mathrm{U}$ studiji je sudjelovala $221 \mathrm{stu}$ dentica u dobi od 16 do 28 godina. Rezultati govore da je tri četvrtine ispitanica $(87,7 \%)$ čulo za samopregled, a ga samo $19 \%$ mjesečno i obavlja. Glavni izvor informacija o samopregledu za većinu djevojaka bili su mediji. Kao razloge zbog kojih ne prakticiraju samopregled ispitanice su navele zaboravnost, nedostatak vremena i uvjerenje da nema problema s njihovim grudima. Studentice čiji je studij zdravstvenog usmjerenja dvostruko su više upućene u samopregled, a tri puta više prakticiraju samopregled od ostalih sudionica. ${ }^{7}$

lako je identificiran niz genskih i okolišnih faktora koji utječu na rizik za rak dojke, etiologija još nije u potpunosti ra- 
zjašnjena, još uvijek nema učinkovitih metoda za primarnu prevenciju i porast incidencije bilježi se kako u manje razvijenim tako i u najrazvijenijim zemljama svijeta. Ono na što se može utjecati jest preživljenje odnosno mortalitet od raka dojke, s obzirom na to da postoji učinkovita metoda ranog otkrivanja mamografijom. ${ }^{8}$ Mjere sekundarne prevencije kao što su mamografija, klinički pregled i samopregled dojki glavne su metode ranog otkrivanja raka dojke. Edukacija u ambulantama primarne zdravstvene zaštite o važnosti provođenja ovih metoda neizbježna je. Krajem 2006. godine započeo je program ranog otkrivanja raka dojke „Mamma”, prvi nacionalni program ranog otkrivanja malignih bolesti u Hrvatskoj. ${ }^{8}$ Međutim postoji nizak odaziv na mamografske skrininge. Kako bismo dobili odgovor na to kompleksno pitanje niskog odaziva, treba razmotriti socijalni, ekonomski, psihološki, etnički, i kulturni kontekst koji okružuje etiologiju bolesti i model intervencije. ${ }^{8}$ Da je edukacija nužna pokazuje nam podatak da čak više od $50 \%$ studentica ne obavlja samopregled dojki. lako već postoje mnoge edukativne radionice i savjetovališta, studentice se na njih ne odazivaju.

Stručnjaci navode i razloge za neobavljanje samopregleda. Oni uključuju anksioznost zbog mogućnosti da se pronađe nešto sumnjivo, lažno uvjerenje kada je rak prisutan, mnoge lažne rezultate te nepotrebnu anksioznost i dijagnostiku kod benignih lezija. Postoji i rizik da žene $s$ dijagnosticiranim benignim lezijama mogu kasnije zanemariti palpabilne, možda maligne, tvorbe na temelju prijašnjeg iskustva. ${ }^{9}$

\section{Zaključak}

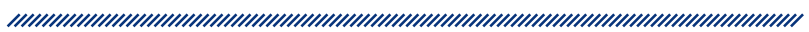

Rano otkrivanje bolesti u asimptomatskoj fazi jedan je od najvažnijih čimbenika unaprjeđenja zdravlja. Javnost je potrebno educirati o primarnim mjerama prevencije koje su usmjerene uklanjanju i redukciji rizičnih čimbenika za karcinom dojke, a isto tako i o mjerama sekundarne prevencije, ranom otkrivanju i liječenju karcinoma. Rano otkrivanje pridonosi boljoj kvaliteti života oboljelih i smanjenju smrtnosti. Uz mamografske preglede, preporučuje se i obavljanje kliničkih pregleda dojki. Samopregled se preporučuje obavljati od rane životne dobi jer može igrati bitnu ulogu u ranom otkrivanju karcinoma dojke. Trebamo imati na umu da samopregledom nije moguće napipati svaki karcinom te da se treba poslužiti i drugim metodama za rano otkrivanje.
Važnu ulogu u edukaciji o važnosti obavljanja samopregleda i načinu provođenja ima zdravstveno osoblje. Samo $15,17 \%$ ispitanica informacije o samopregledu dobilo je od liječnika i medicinske sestre. $U$ ambulantama primarne zdravstvene zaštite potrebno je osigurati više informativnih materijala o važnosti obavljanja samopregleda dojke u ranoj životnoj dobi koji bi bili dostupni svim pacijentima. Potrebno je organizirati i medijske programe kako bi se podignula svijest te informirala i educirala javnost.

Sa samopregledom dojke nije upoznato $12,12 \%$ studentica, što je s obzirom na zdravstveno usmjerenje fakulteta velik broj. Velik broj studentica nikad ne obavlja samopregled (41,44\%), što ukazuje na nedostatak informiranosti o važnosti obavljanja samopregleda dojke. Studentima zdravstvenih studija potrebno je organizirati više predavanja usmjerenih na preventivne aktivnosti kako bi kasnije na svojim radnim mjestima znanje prenijeli na pacijente.

\section{Referencije}

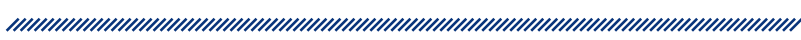

1. Čukljek S. Zdravstvena njega onkoloških bolesnika - nastavni tekstovi. Zagreb; 2014.

2. Hrvatski zavod za javno zdravstvo, Registar za rak Republike Hrvatske. Incidencija raka u Hrvatskoj 2014. Bilten 39; 2016.

3. Tavassoli F.A., Devilee P. World Health Organization Classification of Tumours. Pathology and Genetics of Tumours of the Breast and Female Genital Organs. Lyon: IARC Press; 2003. 60.

4. Guray M., Sahin A. Benign breast disease: Classification, diagnosis and management. The Oncologist. 2006; 5(11): 435-449.

5. Znaor A. Rak dojke u Hrvatskoj - kako stojimo i što očekujemo? Hrvatski časopis za javno zdravstvo. 2008; 13(4): 1130.

6. Gregurić I. Samopregled dojke - nepobitno važna, ali nedovoljno istaknuta metoda. Vaše zdravlje. 2005; 7(40). Dostupno na (http://www.vasezdravlje.com/izdanje/clanak/602/ (pristupljeno 18.3.2018.).

7. Gwarzo UMD., Sabitu K., Idris SH. Knowledge and practice of breast-self examination among female undergraduate students of Ahmadu Bello University Zaria, Northwestern Nigeria. Annals of African Medicine. 2009; 1(8): 55-58.

8. Ceronja I. Odaziv na mamografski skrining. Hrvatski časopis za javno zdravstvo. 2010; 22(7): 537.

9. Austoker J. Breast self examination: Does not prevent deaths due to breast cancer, but breast awareness is still important. British Medical Journal. 2003; 326(7379): 1-2. 


\section{AWARENESS OF BREAST SELF-EXAMINATION AMONG STUDENTS AT THE UNIVERSITY OF APPLIED HEALTH SCIENCES IN ZAGREB}

\author{
1 Antonija Šajnović \\ 1 Ema Šerkić \\ 1 Matea Dumančić \\ 1 Ana Brčina \\ 2 Snježana Čukljek \\ 1 University of Applied Health Sciences, Zagreb, \\ Nursing students \\ 2 University of Applied Health Sciences, Zagreb
}

\begin{abstract}

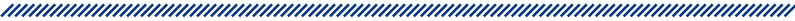

Breast cancer is the leading type of cancer in the female population of Croatia, with incidence and mortality rate significantly higher than the EU average. By monthly breast self-examination, breast cancer can be detected at an earlier stage, which leads to decreased morbidity and mortality. Even though breast self-examination is an easy, fast and inexpensive screening method, a large number of women do not practise this method or lack the necessary knowledge to perform it correctly.

The aim of this study is to assess the knowledge, opinions and prevalence of breast self-examination. The study was conducted at the University of Applied Health Sciences in Zagreb, where 528 female students were included from every study programme (Laboratory Medical Diagnostics, Physiotherapy, Nursing, Radiological Technology, Environmental Health Engineering and Occupational Therapy).
The results show that the majority of participants do not practise breast self-examination. Only $30 \%$ of the participants perform breast self-examination on a monthly basis. As the reason for not performing breast self-examination, the participants most commonly indicated their young age. $24 \%$ of the participants report that they do not know how to perform self-examination.

It is important to encourage the education of future health care professionals about the prevention measures, correct breast self-examination techniques and the importance of early detection of breast cancer, so that they could apply acquired knowledge and skills on their future patients as well as themselves. The organisation of prevention programmes and participation in such programmes is essential in raising awareness of the importance of early detection.

Keywords: breast self-examination, preventive measures, breast cancer 